\title{
Elaboration of technology for manufacturing aluminum-based metal-matrix composite material strengthened with hollow ceramic microspheres for using thereof in underwater equipment
}

\author{
Aleksey Romanov ${ }^{1, *}$, Elena Romanova ${ }^{1}$, and Evgeny Chernyshov ${ }^{1}$ \\ ${ }^{1}$ Nizhny Novgorod State Technical University n.a. R.E. Alekseev, 603950, Nizhny Novgorod, Minin \\ st. 24, Russia
}

\begin{abstract}
This paper deals with the study of capabilities for strengthening an aluminum alloy with hollow ceramic microspheres. The results of the microstructural analysis and the investigation of strength properties for the aluminum-silicon alloying system are described herein. For comparison Experiments have been carried out for comparison both with classical microspheres and with chromium- and chromium-carbide-coated microspheres to increase the melt adhesion to a microsphere
\end{abstract}

\section{Introduction}

The active development of fundamentally new structural materials is currently in great progress. It enables to achieve the qualitative improvement in technical characteristics of machinery and mechanisms. To a large extent metal-matrix composite materials (MMC) shall meet such demands as the purposeful regulation of the composition and the improvement of their manufacturing methods allows to reach quite a new level of performance properties [1-3]. A growing interest in aluminum alloys-based MMC is determined by their improved mechanical and service properties combined with the low density. It should be noted that alongside with the size and degree of saturation the adhesion of the matrix with reinforcing particles has a decisive effect on the mechanical and service properties [4-7]. Furthermore, quite a significant reserve is available for the further improvement of dispersed- filled MMC properties due to developing various manufacturing technologies [8-12].

As one of the possible lines for their application there may be the MMC use for a main body of hard diving suits (Atmospheric Diving Suits).

At present a special type of material such as foam aluminum is also applied in machinery; porous aluminum may have the porosity up to $80 \%$ with the pore size up to 5 $\mathrm{mm}$ and the density of $300 \mathrm{~kg} / \mathrm{m}^{3}$. The strength and plastic properties of the foam

\footnotetext{
*Corresponding author: $\underline{\text { nil_st@nntu.ru }}$
} 
essentially depend on its density [11-13]. However, this material has low mechanical properties and some significant constraints for producing complex-shaped components.

In general, the mechanical properties of such foam materials are conditioned by their three-dimensional isotropic structure and are mainly determined by the behavior of individual structural elements - base-alloy jumpers and the material compression occurs in four stages. At the first stage the deformation of the weakest elements of the frame and the edge non-homogeneities occur under low loads, at the second stage the elastic deformation takes place and at the third stage the said jumpers loose the stability, plastic deformations develop and the compression diagram passes to a flat section, the so-called compression plateau. This process has a cyclic chain character: the loss of the stability by one of the jumpers causes the development of the deformation in adjacent ones and further throughout the entire layer; material layers gradually collapse to the compactification limit, when the pores are finally closed and the deformed material begins to acquire the properties of a compact one. At the fourth stage the stress in the material again increases and it gradually approaches the compact material.

\section{Statement of the Problem}

In paper [14] a technology was proposed for producing a low-density aluminum-based material by introducing into melt hollow ceramic microspheres, including those coated with chromium and chromium carbide to increase the melt adhesion to a microsphere. For these purposes the chemical gas-phase precipitation was used by the MOCVD method (Metal organic chemical vapor deposition [15 - 20].

\section{Experiment Procedure}

In the course of the work there were studied the mechanical properties of aluminum alloy A6 specimens (99.6\% Al, 0.25\% Fe, 0.2\% Si), АК9ч (Si 8-10.5\%, Mn 0.-0,5\%, Cu 0-0.3\%, Mg 0.17-0.3\%, Zn 0-0,3\%), AK12ч (Si 10-13\%, Mn 0-0.4\%, Cu 0-0.2\%) saturated with spheres produced under various technologies.

Hollow ceramic microspheres were pre-pressed under the pressure up to $200 \mathrm{~atm}$. After that sieving was carried out and only those microspheres were used which had passed the test.

Aluminum alloy was melted and brought to the temperature of $750^{\circ} \mathrm{C}$ in an induction crucible furnace, samples of spheres of various volumes were preheated to a temperature of at least $500^{\circ} \mathrm{C}$ within an hour in a muffle furnace. Spheres were introduced into melt with a mixing device. Such obtained alloy was cast out into split molds. After that T6 heat treatment was performed for AK9ch alloy, T5 for AK12ch alloy and A6 alloy was tested without heat treatment. Under similar conditions the casting and heat treatment of alloy samples not saturated with microspheres (base alloys) were performed. The heat treatment of base alloys was carried out simultaneously with microsphere-saturated alloys.

\section{Outcomes of Experiments}

Examples of microstructure of samples saturated with spheres are shown in Figs. 1-3. The tensile strength dependence on the degree of saturation with spheres is shown in Figs 4 - 6. 


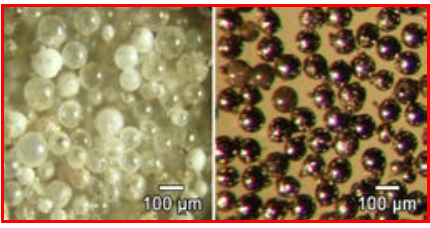

Fig. 1. Aluminosilicate microspheres before (left) metallization and after (right) pyrolytic chromium coating

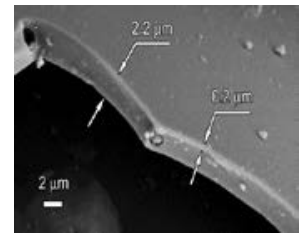

Fig. 2. Coated microsphere surface skew

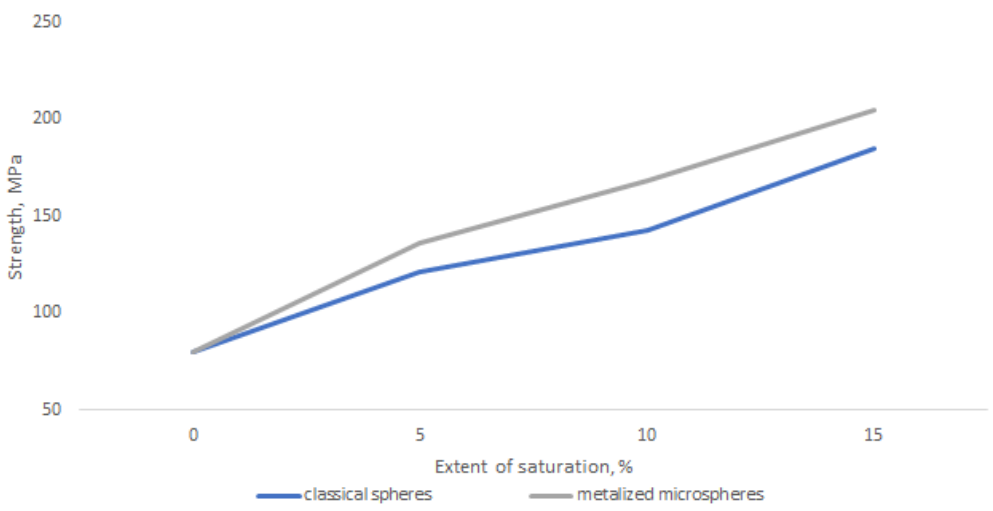

Fig. 4. Dependence of ultimate strength of A6 alloy on saturation degree

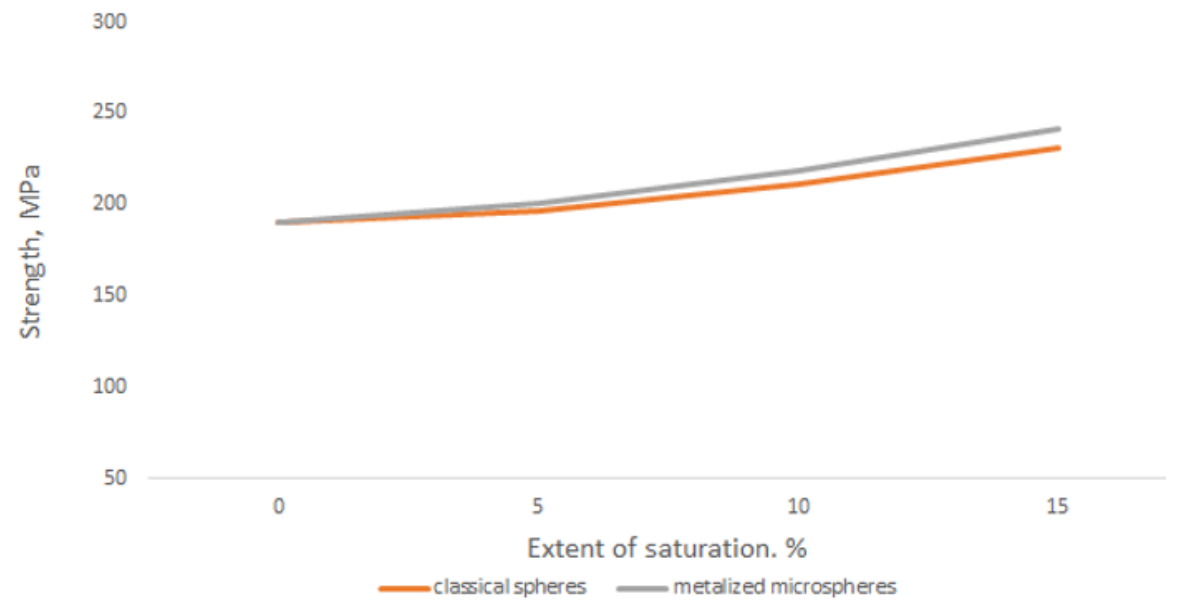

Fig. 5. Dependence of ultimate strength of AK12 T2 alloy on saturation degree 


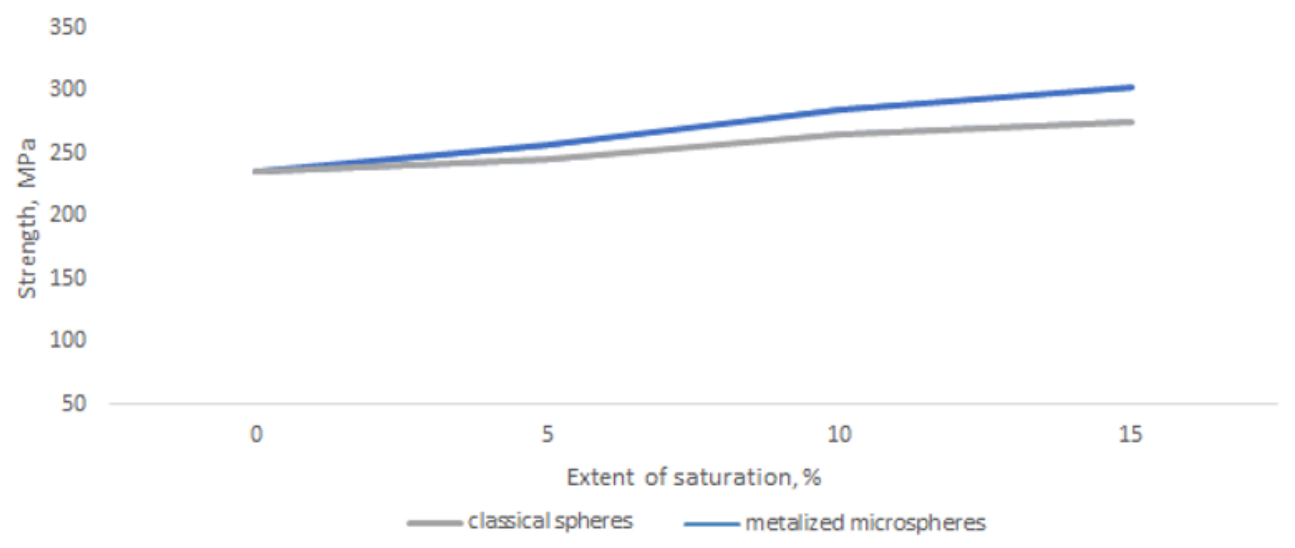

Fig. 6. Dependence of ultimate strength of AK9 T6 alloy on saturation degree

In all cases alloys saturated with particles showed an increase in the tensile strength. A more significant increase in the tensile strength for alloy A6 is conditioned by the "low base", since the strength of the base alloy A6 is about $80 \mathrm{MPa}$.

\section{Conclusions}

The described method of producing alumomatrix MMC saturated with spherical ceramic particles enables to obtain a material with improved mechanical properties as compared to basic aluminum. Moreover, due to hollow microspheres a smaller specific weight and the mass of a component are achieved.

In this case the tensile strength of a material saturated with metalized microspheres is higher relatively to the tensile strength of a material saturated with classical spheres.

The described method of producing aluminum-matrix MMC saturated with spherical ceramic particles enables to obtain a material with improved mechanical properties as compared to basic aluminum. Moreover, due to hollow microspheres a smaller specific weight and the mass of a component are achieved, thus, allowing to more fully implementing MMC potentialities.

The reported study was funded by RFBR according to the research project № 18-3300455 мол_а

\section{References}

1. E. N. Kablov, "Strategic areas for development of materials and processing technology in the period up to 2020,” Aviats. Mater. Tekhnol., No. 5, 7-17 (2012).

2. Yu. A. Kurganova, "Prospects for developing metal matrix composite materials for industrial purposes,” Servis Rossii Rubezh., No. 3(30), 235-240 (2012).

3. D. K. Koli, G. Agnihotri, and R. Purohit, "Properties and characterization of Al-Al2O3 composites processed by casting and powder metallurgy routes (Review)," IJLTET, 2, No. 4, 486-493 (2013).

4. Liu Yao-Hui, Du Jun, Yu Si-rong, and Wang Wei, "High temperature friction and wear behavior of $\mathrm{Al} 2 \mathrm{O} 3$ and/or carbon short fiber reinforced Al-12Si alloy composites," Wear, 256, 275-285 (2004). DOI: 10.1016/S0043-1648(03)00387-9 
5. Chernyshov E.A., Romanov A.D., Romanova E.A. Production of Highly Reinforced Dispersion-Strengthened Composite Material Based on Aluminum by Internal Oxidation, Metallurgist Volume 62, Issue 7-8, 815-819 (2018)

6. Prashant Karandikar, Eric M. Klier, Matthew Watkins, et al., Al/Al2O3 Metal Matrix Composites (MMCs) and Macrocomposites for Armor Applications, Army Research Laboratory ARL-RP-460 MD 21005-5069. September (2013).

7. E. Candan, H. Ahlatci, and H. Cimenoglu, "Abrasive wear behavior of Al-SiC composites produced by pressure infiltration technique,” Wear, 247, 133-138 (2001).

8. A. Gnanavelbabu, K. Rajkumar, and P. Saravanan, "Investigation on the cutting quality characteristics of abrasive water jet machining of AA6061-B4C-hBN hybrid metal matrix composites,” Mater. and Manufacturing Proc., 33, No. 12, 1313-1323 (2018).

9. E. Shankar, S. Balasivanandha Prabu, T. S. Kumar, and M. R. S. John, "Investigation of TiAlN coated roller burnishing on Al(B4C) pMMC workpiece material,” Mater. and Manufacturing Proc., 33, No. 11, 1242-1249 (2018).

10. R. Liu, C. Wu, J. Zhang, et al., "Microstructure and mechanical behaviors of the ultrafine grained AA7075/B4C composites synthesized via one-step consolidation,” J. Alloys and Compounds, No. 748 (2018).

11. A. I. Kovtunov, Yu. Yu. Khokhlov, and S. V. Myamin, "Technology for forming layered composite materials of the titanium-foam aluminum system," Metallurg., No. 4, 6-61 (2015).

12. S. V. Voronin and P. S. Loboda, "Methods for preparing porous materials based on aluminum,” Zv. Samar. Nauch. Tsentr, RAN, 18, No. 4-6, 1068-1074 (2016).

13. S. D. Samuilov and O. A. Troitskii, "New methods for preparing porous metallic materials with a coating and open porosity,” Fund. Prikl. Probl. Tekhnol., No. 3(323), 12-16 (2017).

14. Chernyshov, E.A., Romanov, A.D., Kaverin, B.S., Varyukhin, V.A., Ob’edkov, A.M., Semenov, N.M. Development of Technology for Preparing Composite Material Based on Aluminum Strengthened with Hollow Ceramic Microspheres Metallurgist Volume 62, Issue 11-12, (2019), pp 1255-1260.

15. L. P. Varlamova, V. K. Cherkassov, A. M. Domrachev, et al., "Study of physicomechanical properties of foam urethane-filled aluminum silicate microspheres with a pyrolytic chromium coating,” Zh. Prikl. Khim., 83, No. 3, 494-498 (2010).

16. M. Spirin, "Cerasmic and glass hollow microspheres (information about products and applications,” Lakokras. Mater. Primenen., No. 1-2, 34-35 (2008).

17. B. Zh. Dzhangurazov, G. V. Kozlov, and A. K. Mikitaev, "Effect of the level of interphase adhesion on the structure of nano-filler in nano-composite polymer/organoclay,” Poverkh. Rent. Sinkhr. Neitron, Issled., No. 7, 96-99 (2011).

18. G. A. Razuvaev, G. A. Gribov, G. A. Domrachev, and B. A. Salamatin, Organometal Compounds in Electronics [in Russian], Nauka, Moscow (1972).

19. V. M. Shekunova, A. M. Ob’edkov, E. I. Tsyganova, et al., "Conversion of light alkanes on chromium-containing aluminum silicate ash microspheres," Vestn. YuUrGU, Ser. Khim., 9, No. 3, 37-47 (2017).

20. A. I. Kirillov, A. M. Ob’edkov, V. A. Egorov, et al., "Creation by means of MOCVD technology of nano-structured composite materials based on multiwalled carbon nanotubes,” Nanotekhnika, No. 1, 72-78 (2011). 